\title{
Potential of household environmental resources and practices in eliminating residual malaria transmission: a case study of Tanzania, Burundi, Malawi and Liberia
}

\author{
Henry M. Semakula ${ }^{1,2}$, Guobao Song ${ }^{1}$, Shushen Zhang ${ }^{1}$, Simon P. Achuu ${ }^{3}$
}

1. Key Laboratory of Industrial Ecology and Environmental Engineering (MOE), School of Environmental Science and Technology, Dalian University of Technology, Dalian, 116024, China.

2. College of Agriculture and Environmental Sciences, Department of Environmental Management, Makerere University, Uganda.

3. Faculty of Environment and Natural Resources, Albert Ludwigs University, Freiburg, Germany.

\begin{abstract}
Background: The increasing protection gaps of insecticide-treated nets and indoor-residual spraying methods against malaria have led to an emergence of residual transmission in sub-Saharan Africa and thus, supplementary strategies to control mosquitoes are urgently required.

Objective: To assess household environmental resources and practices that increase or reduce malaria risk among children under-five years of age in order to identify those aspects that can be adopted to control residual transmission.

Methods: Household environmental resources, practices and malaria test results were extracted from Malaria Indicators Survey datasets for Tanzania, Burundi, Malawi and Liberia with 16,747 children from 11,469 households utilised in the analysis. Logistic regressions were performed to quantify the contribution of each factor to malaria occurrence.

Results: Cattle rearing reduced malaria risk between 26\%-49\% while rearing goats increased the risk between 26\%-32\%. All piped-water systems reduced malaria risk between 30\%-87\% (Tanzania), 48\%-95\% (Burundi), 67\%-77\% (Malawi) and 58\%73 (Liberia). Flush toilets reduced malaria risk between 47\%-96\%. Protected-wells increased malaria risk between 19\%-44\%. Interestingly, boreholes increased malaria risk between 19\%-75\%. Charcoal use reduced malaria risk between 11\%-49\%.

Conclusion: Vector control options for tackling mosquitoes were revealed based on their risk levels. These included cattle rearing, installation of piped-water systems and flush toilets as well as use of smokeless fuels.

Keywords: malaria risk, residual transmission, household environmental resources and practices, insecticide-treated nets, indoor-residual spraying

DOI: http://dx.doi.org/10.4314/ahs.v15i3.16

Cite as: Semakula HM, Song G, Zhang S, Achun SP. Potential of household environmental resources and practices in eliminating residual malaria transmission: a case study of Tanzania, Burundi, Malawi and Liberia. Afri Health Sci. 2015;15(3):819-27. doi: bttp://dx.doi. org/10.4314/abs.v15i3.16
\end{abstract}

\section{Introduction}

Malaria is one of the dominant vector-borne diseases threatening humanity in Africa, putting approximately 694 million people at risk ${ }^{1}$. This disease is pronounced in regions where there is little or no interruption in the mosquitoes' life cycle, parasite development cycle $^{2}$ and gonotrophic cycle ${ }^{3}$, a process of alternating blood feed-

\author{
Corresponding author: \\ Guobao Song, \\ Key Laboratory of Industrial Ecology \\ and Environmental Engineering (MOE), \\ School of Environmental Science and \\ Technology, Dalian University of Technology, \\ Dalian, 116024, China. \\ Telephone: (+86) 136-1092-5530, \\ Email: gb.song@dlut.edu.cn
}

ing and laying of eggs. Recently, a substantial decline in malaria cases has been documented ${ }^{4,5}$ especially in Sub-Saharan Africa (SSA) where widespread use of insecticide-treated nets (ITNs) and indoor-residual spraying (IRS) interventions have been promoted ${ }^{1}$. However, this achievement is momentary given the fact that ITNs and IRS methods alone cannot effectively eliminate malaria transmission to zero due to various limitations. Both methods are limited in scope, for example, IRS method only kills or repels mosquitoes which feed and rest indoors, while ITNs prevent night mosquito bites just around the beds ${ }^{6,7}$. Moreover, both methods affect mosquitoes which target human blood sources yet the majority of mosquitoes obtain most of their blood meals from animals ${ }^{6}$.

These limitations provide ample opportunity for outdoor active mosquitoes to multiply while sustaining 
some level of transmission beyond the reach of insecticide-treated surfaces. Besides, widespread use of ITNs and IRS has led to an apparent shift in mosquito behavioural traits ${ }^{8}$ hence presenting a major ecological obstacle. For example both interventions have been observed to stimulate insecticide avoidance and early-exit behaviors among indoor-feeding vectors ${ }^{6}$ as well as causing the emergency of insecticide-resistant mosquitoes ${ }^{9,10}$. They have also led to an increase in mosquito populations which feed and rest outdoors as well as those that become active early in the morning or evening when people have no protection ${ }^{11}$.

With these behavioural shifts, residual transmission can occur rapidly in communities where large human populations and mosquitoes cohabitate as it has been evidenced in some regions of Uganda, Tanzania and Kenya where ITNs and IRS methods are being implemented $^{12}$. Residual transmission is exacerbated by human movements through exportation and importation of malaria parasites among regions ${ }^{13}$. It is also caused by climate change which enhances mosquito breeding and pathogen development ${ }^{14,15}$ and more importantly, the proximity of natural or artificial mosquito breeding sites to human settlements ${ }^{16}$.

With the increasing protection gaps of ITNs and IRS methods coupled with a shift in mosquitoes' behaviour traits, achieving malaria elimination will require environmentally based interventions which minimize vector propagation as well as reducing human-vector contact outside human habitations ${ }^{17}$. Nevertheless, despite the fact that household environmental resources and practices such as livestock rearing are crucial in reducing malaria transmission, they have not been sufficiently identified and quantitatively evaluated to justify their contribution $^{6}$. To address this knowledge gap, this study aimed at assessing household environmental resources and practices that influenced malaria risk among children under-five years of age and further identify those resources that can be adopted to control malaria transmission.

\section{Methods \\ Data sources}

Nationally representative population based datasets from the Malaria Indicators Surveys (MIS $)^{18}$ conducted in SSA were used. The criteria used to select datasets of countries analysed in this study were: 1) datasets which were publicly available and 2) those containing sufficient information on malaria test results as well as household environmental resources and practices such as, drinking water sources, fecal disposal methods, types of cooking fuel and types of livestock/poultry kept. Datasets of four countries (Burundi, Liberia, Malawi and Tanzania) met these criteria and were used. In these surveys, representative samples were obtained using same probability sampling techniques consisting of a two-stage cluster sampling and probability proportional to estimate cluster size and sampling error. Standardised questionnaires were designed to collect information on the social, economic and environmental aspects of households. Rapid Diagnostic Test (RDT) and the Blood Smear Test (BST) were used to test malaria parasitaemia among children under-five years of age after getting consent from household heads. Further details on data collection exercises can be found on MIS website $^{18}$.

\section{Study population, sample size and variable selec- tion}

A total of 22,472 households were involved in the MIS for the four countries, but in this study, only 11,469 households with 16,747 malaria-tested children were purposively selected. This was done to minimize the interference of those households without both children and test results in the analysis. In the study, malaria RDT results were used in the analysis. The response variable for each selected country was the malaria RDT results (positive or negative). The explanatory variables were those household environmental resources and practices that potentially influenced the survival, feeding and breeding of mosquitoes. Explanatory variables were categorised (Table 1). 
Table 1. Selected explanatory variables that were used for modeling

\begin{tabular}{|c|c|}
\hline Explanatory variable & Categories \\
\hline \multirow[t]{10}{*}{ Drinking-water sources } & Household used/fetched water from \\
\hline & 1. Piped water in yard/dwelling \\
\hline & 2. Public stand-pipe \\
\hline & 3. Private taps \\
\hline & 4. Borehole \\
\hline & 5. Protected well \\
\hline & 6. Unprotected well \\
\hline & 7. Protected spring \\
\hline & 8. Unprotected spring \\
\hline & 9. River/lake/reservoir/pond/stream \\
\hline Time required to fetch water & Intervals of 10 minutes per water source \\
\hline \multirow[t]{7}{*}{ Fecal-disposal mechanism } & Household used or had \\
\hline & 1. No toilet facility/bush/field \\
\hline & 2. Flush toilets \\
\hline & 3. Ventilated improved pitlatrines \\
\hline & 4. Composting toilet \\
\hline & 5. Pitlatrines with slab \\
\hline & 6. Pitlatrines without slab \\
\hline \multirow[t]{5}{*}{ Livestock/poultry kept } & Household kept \\
\hline & 1. Cattle \\
\hline & 2. Goats/sheep \\
\hline & 3. Poultry \\
\hline & 4. Pigs \\
\hline \multirow[t]{3}{*}{ Types of cooking fuel } & Household used \\
\hline & 1. Firewood \\
\hline & 2. Charcoal \\
\hline
\end{tabular}

\section{Data analysis}

Given the categorical nature of the variables, both univariate and multivariate logistic regression models were developed separately for each country for comparison purposes. The analysis was designed to reveal those explanatory variables that were significant and those that were not, rather than to find the best models for predictive purposes. Each variable was first assessed against the RDT results using univariate logistic analysis and the likelihood ratio test. Variables significant at p-value $<0.05$ formed a candidate list for the multivariate logistic regressions. All categorised time intervals for the time required to fetch water were entered into the multivariate model. Variables such as child age, urban resi- dence and use of ITNs were added as covariates in the final model to avoid omitted-variable bias due to confounding. MIS-generated population sample weights were used in all models to obtain representative results with p-value $<0.05$ used for all analyses to determine the statistical significance. The analysis was conducted by JMP 10, a product of Statistical Analysis System.

\section{Results}

Table 2 shows country-specific logistic regressions of explanatory variables tested against malaria RDT results of children under-five years. The adjusted odd ratios of the time required to fetch water against malaria risk across the four countries were plotted (Figure 1). 
Table 2. Household environmental resources and practices associated with malaria risk among children under-five years of age

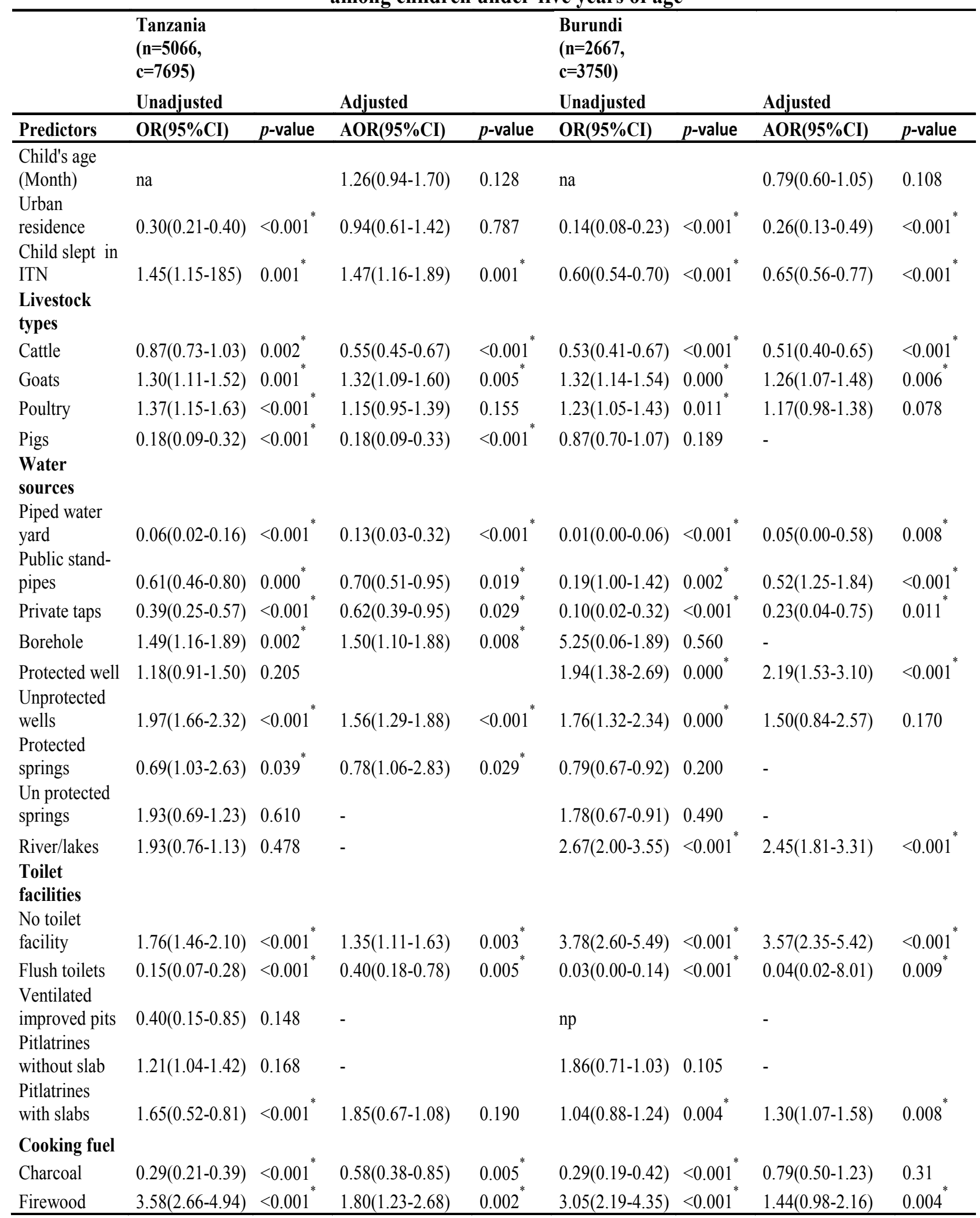


Table 2. Household environmental resources associated with malaria risk among children under-five years of age (Continued)

\begin{tabular}{|c|c|c|c|c|c|c|c|c|}
\hline & $\begin{array}{c}\text { Malawi } \\
(\mathrm{n}=1625, \mathrm{c}=2 \\
\text { Unadjustec }\end{array}$ & & Adjusted & & $\begin{array}{l}\begin{array}{l}\text { Liberia } \\
(n=2111, c=3 \\
\text { Unadjuste }\end{array} \\
\end{array}$ & $\begin{array}{l}\text { 187) } \\
\text { d }\end{array}$ & Adjusted & \\
\hline Predictors & $\begin{array}{l}\text { OR(95\%C } \\
\text { I) }\end{array}$ & $\begin{array}{l}p- \\
\text { value }\end{array}$ & $\operatorname{AOR}(95 \% \mathrm{CI})$ & $p$-value & $\begin{array}{l}\text { OR(95\% } \\
\text { CI) }\end{array}$ & $\begin{array}{l}p \text { - } \\
\text { value }\end{array}$ & $\begin{array}{l}\text { AOR(95\% } \\
\text { CI) }\end{array}$ & $p$-value \\
\hline $\begin{array}{l}\text { Child's age } \\
\text { (Month) }\end{array}$ & na & & $1.85(1.33-2.56)$ & $0.000^{*}$ & na & & $\begin{array}{l}2.10(1.59- \\
2.80)\end{array}$ & $<0.001$ \\
\hline Urban residence & $\begin{array}{l}0.18(0.12- \\
0.25) \\
0.84(0.70-\end{array}$ & $\begin{array}{l}<0.00 \\
1^{*}\end{array}$ & $0.39(0.25-0.60)$ & $\begin{array}{l}<.000 \\
1^{*}\end{array}$ & $0.36(0.31-0.42)$ & $\begin{array}{l}<0.00 \\
1^{*}\end{array}$ & $\begin{array}{l}0.72(0.57- \\
0.92) \\
0.99(0.85-\end{array}$ & $0.008^{*}$ \\
\hline Child slept in ITN & $1.00)$ & $0.048^{*}$ & $0.88(0.73-1.07)$ & 0.202 & $0.93(0.80-1.08)$ & 0.331 & $1.17)$ & 0.945 \\
\hline Livestock types & & & & & & & & \\
\hline Cattle & $\begin{array}{l}0.66(0.43- \\
0.98) \\
1.15(0.94-\end{array}$ & $0.040^{*}$ & $0.54(0.35-0.83)$ & $0.005^{*}$ & $0.72(0.23-5.05)$ & $0.020^{*}$ & $\begin{array}{l}0.74(0.55- \\
1.00)\end{array}$ & $0.047^{*}$ \\
\hline Goats & $\begin{array}{l}1.40) \\
1.19(1.01-\end{array}$ & 0.170 & - & & $1.17(0.90-1.51)$ & 0.410 & - & \\
\hline Poultry & $\begin{array}{l}1.41) \\
1.15(0.86-\end{array}$ & $0.040^{*}$ & $1.01(0.84-1.21)$ & 0.933 & $1.25(1.07-1.45)$ & 0.560 & - & \\
\hline Pigs & $1.53)$ & 0.400 & - & & $1.51(1.03-2.23)$ & 0.360 & - & \\
\hline Water sources & $0.1600 .09-$ & $<000$ & & $<000$ & & & $0.42(0.68$ & \\
\hline $\begin{array}{l}\text { Piped water yard } \\
\text { Public stand- } \\
\text { pipes }\end{array}$ & $\begin{array}{l}0.28) \\
0.27(0.19- \\
0.36) \\
1.31(1.11-\end{array}$ & $\begin{array}{l}1^{*} \\
<0.00 \\
1^{*}\end{array}$ & $\begin{array}{l}0.23(0.12-0.43) \\
0.33(0.23-0.47)\end{array}$ & $\begin{array}{l}1^{*} \\
<.000 \\
1^{*}\end{array}$ & $\begin{array}{l}0.64(0.32-1.20) \\
0.10(0.05-0.17)\end{array}$ & $\begin{array}{l}0.020^{*} \\
<0.00 \\
1^{*}\end{array}$ & $\begin{array}{l}2.88) \\
0.27(0.13- \\
0.51) \\
1.19(0.36-\end{array}$ & $\begin{array}{l}0.346 \\
<0.00 \\
1^{*}\end{array}$ \\
\hline Borehole & $\begin{array}{l}1.55) \\
1.79(0.53-\end{array}$ & $0.000^{*}$ & $1.75(0.61-0.93)$ & $0.009^{*}$ & $1.70(0.22-1.98)$ & $0.010^{*}$ & $\begin{array}{l}3.60) \\
1.36(1.04-\end{array}$ & $0.003^{*}$ \\
\hline Protectedwell & $\begin{array}{l}1.16) \\
2.41(1.89-\end{array}$ & $\begin{array}{l}0.020^{*} \\
<0.00\end{array}$ & $1.44(0.25-0.78)$ & $0.005^{*}$ & $1.17(1.01-1.37)$ & $0.040^{*}$ & $1.78)$ & $0.025^{*}$ \\
\hline Unprotected wells & $\begin{array}{l}3.07) \\
0.33(0.02-\end{array}$ & $1^{*}$ & $1.22(0.75-2.00)$ & 0.412 & $1.73(0.55-0.95)$ & 0.200 & - & \\
\hline Protected springs & $1.85)$ & 0.220 & - & & $0.10(0.00-2.88)$ & 0.220 & - & \\
\hline $\begin{array}{l}\text { Un protected } \\
\text { springs }\end{array}$ & $\begin{array}{l}1.64(0.98- \\
2.78) \\
1.64(1.07-\end{array}$ & $0.060^{*}$ & $1.90(0.46-1.78)$ & 0.768 & $1.93(1.27-2.96)$ & $\begin{array}{l}0.000^{*} \\
<0.00\end{array}$ & $\begin{array}{l}1.65(1.01- \\
2.71) \\
1.55(1.12-\end{array}$ & $0.047^{*}$ \\
\hline River/lakes & $2.53)$ & 0.240 & - & & $1.79(1.46-2.19)$ & $1^{*}$ & $2.16)$ & $0.009^{*}$ \\
\hline Toilet facilities & & & & & & & & \\
\hline No toilet facility & $\begin{array}{l}2.00(1.59- \\
2.51) \\
0.00(0.00-\end{array}$ & $\begin{array}{l}<0.00 \\
1^{*}\end{array}$ & $1.66(1.20-2.30)$ & $0.002^{*}$ & $1.62(1.40-1.88)$ & $\begin{array}{l}<0.00 \\
1^{*} \\
<0.00\end{array}$ & $\begin{array}{l}1.24(0.82- \\
1.28) \\
0.53(0.39-\end{array}$ & $\begin{array}{l}0.004 \\
<0.00\end{array}$ \\
\hline $\begin{array}{l}\text { Flush toilets } \\
\text { Ventilated }\end{array}$ & $\begin{array}{l}0.14) \\
0.54(0.33-\end{array}$ & 0.200 & - & & $0.31(0.24-0.39)$ & $1^{*}$ & $0.73)$ & 1 \\
\hline $\begin{array}{l}\text { improved pits } \\
\text { Pitlatrines } \\
\text { without slabs }\end{array}$ & $\begin{array}{l}0.85) \\
1.94(0.79- \\
1.13)\end{array}$ & 0.100 & - & & $0.95(0.66-1.36)$ & 0.780 & - & \\
\hline
\end{tabular}

*indicates statistical significance at $p$-value $<0.05$. Dashes indicate that the predictors were excluded from the multivariate regressions. Abbreviation $\mathbf{n}$ and $\mathbf{c}$ indicate total number of households and children respectively while na stands for not applicable and $\mathbf{n p}$ represents no ventilated improved pits. All $p$-values are within the limits of $95 \%$ confidence interval. 


\section{Figure 1. Relationship between household proximity to different drinking water sources and malaria risk among children}

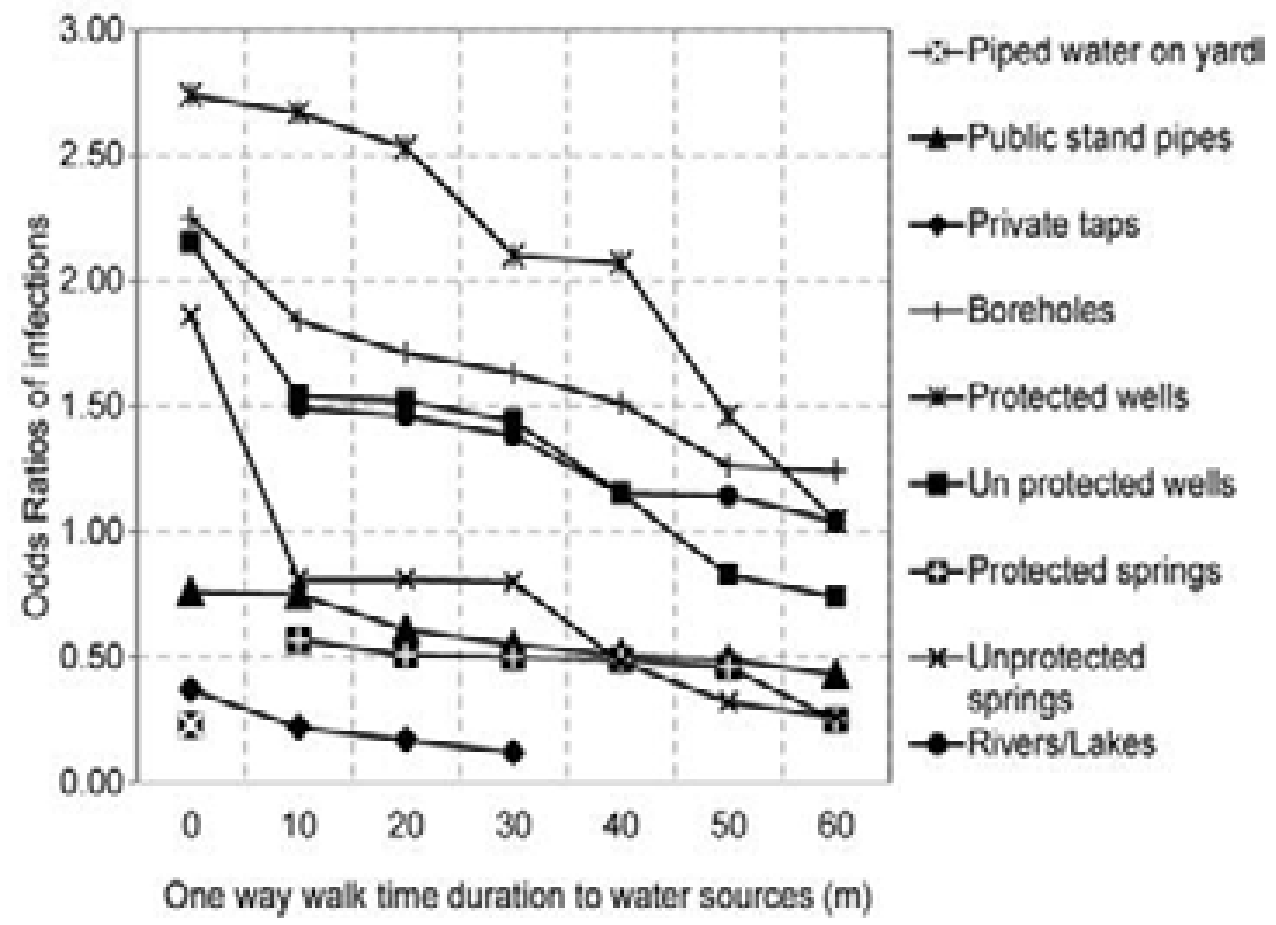

\section{Discussion}

The practice of keeping livestock influenced malaria risk greatly. The adjusted models predicted that malaria risk decreased significantly between 26\%-46\% among households rearing cattle. There are two possible explanations to this observed protective effect. Cattle generate significant amounts of olfactory cues which attract large numbers of mosquitoes ${ }^{19,20}$, and this reduces human exposure to mosquito bites in and around homesteads. Added to this, is a shift in mosquito biting behaviourial traits, that is, from people to cattle which is caused by the continuous use of ITNs and IRS methods $^{21}$. With these scenarios, cattle rearing can benefit malaria control programs in three ways.

First, mosquitoes become frequently attracted to insecticide-treated cattle which reduce their abundance and infection abilities ${ }^{22}$. Second, cattle are not reservoir hosts for malaria parasites, so the transmission cycle is broken when mosquitoes feed on cattle ${ }^{23}$.

Third, mosquitoes are part of the broader ecosystem of interactions with other organisms ${ }^{17}$ and their behavioral shift to feeding on cattle subject them to predators such as small birds and reptiles. However, integrating malaria control priorities into animal husbandry is paramount since it can ensure that insecticides applied to cattle are those with a purely toxic mode of action without irritant or repellent properties that could chase away mosquitoes ${ }^{6}$. Nevertheless, the models also predicted an increased risk due to goat rearing in Tanzania (32\%) and Burundi (26\%). Similarly, keeping poultry increased malaria risk between $0.1 \%-17 \%$, but this increase was not significant.

Drinking water sources were key determinants that influenced malaria risk. The adjusted models indicated that households which used water from piped-water systems (i.e. piped-water on yards, public stand-pipes and private taps) had their malaria risk reduced significantly ranging from $30-87 \%$ in Tanzania, $48 \%-95 \%$ in Burundi, 67\%-77\% in Malawi and 58\%-73 in Liberia. There are two explanations for the protective effects of piped-water systems and these can be exploited to reduce residual transmission.

First, piped-water systems are normally located either in or close to households, which reduces the time required to fetch water, thus allowing parents to have ample time to guard their children against mosquito bites. Second, the enclosed nature of piped-water systems significantly reduce the number of mosquito breeding sites $^{24}$, thereby prolonging the mosquito gonotrophic cycle as 
well as interrupting malaria transmission ${ }^{3}$. For households which used water from unprotected wells, malaria risk increased between 22\%-56\%, though this increase was only significant in Tanzania. This increase is due to the fact that wells serve as meeting places for humans and mosquitoes ${ }^{24}$, provide oviposition sites ${ }^{16}$ and shorten the gonotrophic cycle ${ }^{3}$ especially when located near human habitations. Interestingly, the models predicted that boreholes significantly increased malaria risk between 19\%-75\%. An explanation to this result is that most boreholes in SSA are normally installed in communities and are usually congested with long queues compared with piped water systems. Thus, when a single borehole with a poorly maintained drainage channel ${ }^{25}$ is surrounded by a large number of residents, mosquito biting and parasite transmission among children left at home are inevitable in such communities (Figure 1).

Household proximity to water sources had significant influence on malaria risk (Figure 1). Households with piped-water systems on their premises had a low malaria risk and this continued to reduce gradually as walktime duration to fetch water increased. This reduction is attributed to a fact that piped-water systems discourage oviposition $^{24}$ and thus makes it difficult for mosquitoes to complete their gonotrophic cycles. Households which had boreholes, unprotected springs, protected and unprotected wells on their premises had a high malaria risk and as time to obtain water from these water sources increased, the risk kept on reducing gradually. A possible explanation to this result is that open water sources in household premises created potential breading sites that shortened the gonotrophic cycles while increasing transmission. As fetching water time increased, malaria risk reduced due to prolonged gonotrophic cycles attributed to limited long-range flight abilities of mosquitoes ${ }^{3}$. However, although distant water sources reduced malaria risk, this observation should not jeopardize efforts geared to improve water access near households, because reducing the time to fetch water has been observed to improve child health ${ }^{26}$. Thus, improving drainage channels, reducing unnecessary open water surfaces and implementing larvicidal treatments is crucial in reducing malaria risk of these water sourc$\mathrm{es}^{27}$.

Regarding household sanitation, malaria risk varied greatly with different types of human fecal disposal methods. The adjusted models indicated that house- holds with flush toilets had their malaria risk reduced between 47\%-96\%. Households which did not have any form of toilet facility were at a high risk ranging from $24 \%-66 \%$. This increase was not surprising because mosquitoes have overtime started changing their breeding preference to contaminated surroundings ${ }^{16}$. Interestingly, households which used pitl atrines with slabs had their malaria risk increased between 10\%-85\%. An explanation to this finding is that when water is used for anal cleansing, it creates breeding sites inside the pit latrines ${ }^{16}$. Additionally, poorly maintained pit latrines can become ideal places for mosquito breeding when floods occur during the rainy season. In such situation, mosquitoes can only be suppressed when expanded polystyrene beads are used ${ }^{27}$.

Household domestic fuel had some influence on malaria risk. The models estimated that the use of firewood for cooking greatly increased the risk between $22 \%-75 \%$. The reasons for this increase are varied. First, smoke from domestic fuel increases the frequency with which ITNs are washed, thus reducing their effectiveness in repelling or killing mosquitoes ${ }^{28}$. Moreover, women and children gather much of the firewood in SSA countries which exposes them to frequent mosquito bites in the forests ${ }^{8}$. Additionally, the shift in mosquito behaviour from indoor late-night biting to outdoor early-evening biting ${ }^{11}$ coincides well with major outdoor cooking activities in most homesteads of SSA countries. Charcoal use lowered malaria risk between 11\%-49\% with significance of this reduction presented in Tanzania. Although charcoal use may have this protective effect, it is one of the fundamental drivers of deforestation in SSA, thus, its use in malaria control programs is not advisable in both short and long run. Alternatively, promotion of other renewable indoor cooking fuels such as gas, solar and electricity can be paramount in reducing outdoor evening mosquito bites which normally occur during meal preparations. Besides, some plant leaves have been proved to be able to function as mosquito repellent protecting individuals from host-seeking mosquitoes according to a valuable review from Maia and Moore ${ }^{29}$. Therefore, policies to effectively manage forest resources in malaria control should be comprehensively considered in future prevention programs.

\section{Conclusion}

In order to sustain and consolidate the recent gains achieved by ITNs and IRS towards malaria reduction 
in SSA, significant investment is required to promote supplementary environmentally- based vector control strategies that can divert mosquitoes from humans, suppress vector propagation and parasite development. This study provided useful insights of vector control options for tackling mosquitoes that persist and mediate residual transmission. These include cattle rearing, use of flush toilets as well as installation of piped-water systems mainly piped-water on yards, public standpipes and private taps. Additionally, the use of indoor smokeless fuels like gas, electricity, and solar energy can reduce exposure to outdoor mosquito bites. We believe that these vector control options can be used to increase the efficacy of ITNs and IRS interventions and produce synergistic effects in reducing malaria risk among children and other vulnerable people.

\section{Competing interests}

The authors declare that they have no competing interests.

\section{Acknowledgment}

The study is funded by Fundamental Research Funds for the Central Universities of China (DUT14LAB17), and in part by the National Natural Science Foundation of China (41001354).

\section{References}

1. WHO. World malaria report 2013. http://www. who.int/malaria/publications/ world_ malaria_ report 2013/en/. Accessed 30th January 2014.

2. Aly ASI, Vaughan AM, Kappe SHI. Malaria parasite development in the mosquito and infection of the mammalian host. Annu Rev Microbiol 2009; 63:195-221.

3. Gu W, Regens JL, Beier GC, Novak RJ. Source reduction of mosquito larval habitats has unexpected consequences on malaria transmission. Proc Natl Acad Sci USA 2006; 103:17560-17563.

4. Noor AM, Kinyoki DK, Mundia CW, Kabaria CW, Mutua JW, Alegana VA, et al. The changing risk of plasmodium falciparum malaria infection in Africa: 200010: a spatial and temporal analysis of transmission intensity. Lancet 2014; 383:1739-1747.

5. O’Meara WP, Mangeni JN, Steketee R, B. Greenwood

B. Changes in the burden of malaria in Sub- Saharan Africa. Lancet Infect Dis 2010; 10:545-555.

6. Killeen GF: Characterising, controlling and eliminating residual malaria transmission. Malar J 2014; 13:1-22.

7. Fullman N, Burstein R, Lim S, Medlin C, Gakidou E. Nets, spray or both? The effectiveness of insecticide-treated nets and indoor residual spraying in reduc- ing malaria morbidity and child mortality in Sub-Saharan Africa. Malar J 2013; 12:1-10.

8. Enayati A, Hemingway J. Malaria management: past, present, and future. Annu Rev Entomol 2010; 55:569-591. 9. Maxmen A. Malaria surge feared. Nature 2012; 485:293.

10. Trape JF, Tall A, Diagne N, Ndiath O, Ly AB, Faye $\mathrm{J}$, et al. Malaria morbidity and pyrethroid resistance after the introduction of insecticide-treated bednets and artemisinin-based combination therapies: a longitudinal study. Lancet Infect Dis 2011; 11:925-932.

11. Gatton ML, Chitnis N, Churcher T, Donnelly MJ, Ghani AC, Godfray HCJ, et al. The importance of mosquito behavioural adaptations to malaria control in Africa. Evolution 2013; 67:1218-1230.

12. Durnez L, Coosemans M: Residual transmission of malaria: An old issue for new approaches. In Anopheles mosquitoes,new insights into malaria vectors. Edited by Manguin S. InTech; 2013:671-704.

13. Wesolowski A, Eagle N, Tatem AJ, Smith DL, Noor AM, Snow RW, et al. Quantifying the impact of human mobility on malaria. Science 2012; 338:267-270.

14. Paaijmans KP, Blanford S, Bell AS, Blanford JI, Read AF, Thomas MB. Influence of climate on malaria transmission depends on daily temperature variation. Proc Natl Acad Sci USA 2010; 107:15135-15139.

15. Yamana TK, Eltahir EAB. Projected impacts of climate change on environmental suitability for malaria transmission in West Africa. Environ Health Perspect 2013; 121:1179-1186.

16. De Silva PM, Marshall JM. Factors contributing to urban malaria transmission in Sub-Saharan Africa: A systematicreview. J Trop Med 2012; 2012:1-11.

17. Ferguson HM, Dornhaus A, Beeche A, Borgemeister C, Gottlieb M. Ecology: A prerequisite for malaria elimination and eradication. PLoS Med 2010; 7:1-7. 18. MIS. Available: http://www.malariasurveys.org/. Accessed 28th September 2013

19. Mahande A, Mosha F, Mahande J, Kweka E. Feeding and resting behaviour of malaria vector, anopheles arabiensis with reference to zooprophylaxis. Malar J 2007; 6:1-6.

20. Takken W, Verhulst NO. Host preferences of blood-feeding mosquitoes. Annu Rev Entomol 2013; 58:433-453.

21. Iwashita H, Dida GO, Sunahara T, Futami K. Njenga SM, Chaves LF, et al. Push by a net, pull by a cow: can zooprophylaxis enhance the impact of insecticide treated bed nets onmalaria control? Parasit Vectors 2014; $7: 1-15$. 
22. Rowland M, Durrani N, Kenward M, Mohammed $\mathrm{N}$, Urahman H, Hewitt S. Control of malaria in Pakistan by applying deltamethrin insecticide to cattle: a community-randomised trial. Lancet 2001; 357:1837-1841.

23. Saul A. Zooprophylaxis or zoopotentiation: the outcome of introducing animals on vector transmission is highly dependent on the mosquito mortality while searching. Malar J 2003; 2:1-18.

24. Impoinvil DE, Keating J, Chowdhury R, Duncan $\mathrm{R}$, Cardenas G, Ahmad S, et al. The association between distance to water pipes and water bodies positive for anopheline mosquitoes (Diptera: Culicidae) in the urban community of Malindi, Kenya. J Vector Ecol 2007; 32:319-327.

25. Foster T. Predictors of sustainability for community-managed hand-pumps in Sub-Saharan Africa: Evi- dence from Liberia, Sierra Leone, and Uganda. Environ Sci Technol 2013; 47:12037-12046.

26. Pickering AJ, Davis J. Freshwater availability and water fetching distance affect child health in Sub-Saharan Africa. Environ Sci Technol 2012; 46:2391-2397.

27. Keiser J, Singer BH, Utzinger J. Reducing the burden of malaria in different eco- epidemiological settings with environmental management: a systematic review. Lancet Infect Dis 2005; 5:695-708.

28. Biran A, Smith L, Lines J, Ensink J, Cameron M. Smoke and malaria: are interventions to reduce exposure to indoor air pollution likely to increase exposure to mosquitoes. Trans R Soc Trop Med Hyg 2007; 101:10651071.

29. Maia MF, Moore SJ. Plant-based insect repellents: a review of their efficacy, development and testing. Malar J 2011; 10: 1-15. 